\title{
Controversial impact of experimental soil inoculant containing Beauveria bassiana and Metarhizium anisopliae on Sitophilus granarius
}

\author{
Sándor Keszthelyi ${ }^{1 *} \mathbb{0}$, Petra Grünvald ${ }^{2}$ and Ferenc Pál-Fám ${ }^{1}$
}

\footnotetext{
${ }^{1}$ Department of Agronomy, Institute of Agronomy, Hungarian University of Agriculture and Life Sciences, Kaposvár Campus, Guba S. u. 40, H-7400 Kaposvár, Hungary

${ }^{2}$ Institute of Animal Physiology and Animal Nutrition, Department of Farm Animal Nutrition, Hungarian University of Agriculture and Life Sciences, Kaposvár Campus, Guba S. u. 40, H-7400 Kaposvár, Hungary
}

\section{RESEARCH ARTICLE}

Received: September 27, 2020 • Accepted: December 20, 2020

Published online: July 7, 2021

(c) 2020 The Author(s)

\begin{abstract}
The insecticidal efficacy of the experimental bioinoculants (Natur Nova, Natur Agro Hungary Ltd., Hungary) containing Beauveria bassiana (Bals.-Criv). Vuill. and Metarhizium anisopliae Metschnikoff against stored product pests modelled by granary weevil, Sitophilus granarius L. was evaluated on wheat in laboratory tests. In order to comparability, two applications were also set up: one purely ash-treated grain treatment against wireworms and a soil-injected one. Our results confirmed that some biopesticides can exert unexpected effect on non-target arthropods. However, the examined biopesticides were as empirically effected against the target arthropods regarding wireworms. Nevertheless, the application exempt from ash of the examined bioinoculants Natur Nova containing B. bassiana and M. anisopliae were not suitable for the elimination of the stored product pests modelled by S. granarius. In contrast, the putative plant protection effect of these biopesticides was observed in the course of applying the agents in the recommended environment and pest species as well as when applying them with ash carrier.
\end{abstract}

\section{KEYWORDS}

biopesticide, entomopathogenic fungi, environmental friendly protection, granary weevil, soil inoculant

*Corresponding author. E-mail: ostrinia@gmail.com 


\section{INTRODUCTION}

Beauveria bassiana (Balsamo) Vuillemin (Ascomycota: Hypocreales) and Metarhizium anisopliae (Metschnikoff) (Ascomycota: Hypocreales) Sorokin are two anamorphic entomopathogenic ascomycetes from the Cordicipitaceae family, Hypocreales (Index Fungorum, 2020) order, which attack several insects. Both entomopathogenic microfungi grow naturally in soils across the world (Rehner, 2005; Fernando et al., 2012). These species can be found in different soils both in natural habitats and arable fields. Beauveria bassiana can parasitize more than 700 insect hosts (Inglis et al., 2001). In addition, this fungus was reported to be endophytic in plants (e.g. corn) and it probably functions as an adaptive protector in plants against herbivorous insects (White et al., 2002). M. anisopliae was also documented to be associated with plants in the rhizosphere (Hu and St. Leger, 2002).

Both species require arthropod hosts to develop the mitosporic conidia; they quiesce in conidial stage in the soil prior to infecting a host. Insects are considered to be the most important sources of organic matter for both species (Meyling and Eilenberg, 2007). Pathogenic features of these entomopathogens are very complex and various. These fungi attack the integument of the host using an enzymatic complex. M. anisopliae and Beauveria bassiana attack insect hosts via attachment to cuticular substrata and the production of enzymes for the degradation and penetration of insect cuticle (Rustiguel, 2012; Pedrini et al., 2013). The dispersal of the fungi can occur via infected migrating insects (Feng et al., 2004), as well as passively by the air (Ulevicius et al., 2004).

These biological agents are being used as biological insecticides to control a number of pests such as termites, thrips, whiteflies, locusts, aphids and beetles (Roberts and Hajek, 1992; Fernando et al., 2012).

There are many kind and pestiferous arthropod pests in stored product. These insects can be divided two well-determined groups. The first contains the so-called primary, which is able to attack the grain alone, for example Sitophilus granarius L. and Rhizoperta dominica L. The members of the second group can only be caused damage in their host if these plants have already damaged by the primary pest, as Tribolium castaneum Herbst, Oryzaephilus surinamensis L. Their importance was emphasized the most global economic phytosanitary and sometimes human concern. The granary weevil (S. granarius L.) (Coleoptera: Curculionidae) is a serious pest of stored grains and is a common pest in all continents (Howe and Hole, 1968). It can cause significant damage to harvested and stored grains and may drastically decrease crop yields. All larval stages and the pupal stage occur within the grain. The larvae feed inside the grain until pupation. The life cycle takes approximately 1.5 months (Surtees, 1965).

Our aim in the present study was to test the efficacy of two different soil-applied bio preparations (active ingredients $B$. bassiana and $M$. anisopliae) produced by Natur Agro Hungary Ltd. against the stored product-pests using granary weevil as a model species. In addition, our objective was to examine the influence of the dose rates of these biopesticides on weevil mortality and progeny production applying or omitting ash carrier.

\section{MATERIAL AND METHODS}

\section{Experimental materials}

Untreated, clean and infestation-free wheat grains were used for the experiments. The grains were treated with two soil bioinsecticides prepared according to the manufacturer instructions 
(Natur Agro Hungary Ltd.). Physical and biological parameters of experimental pesticides were as follows:

- Natur Nova 1: liquid soil inoculant containing Beavaria bassiana (hereinafter: NN B. bassiana); concentration: $1 \times 10^{6}$; $\mathrm{pH}: 4.2 \pm 0.5$; dry matter content $0.3 \mathrm{~m} / \mathrm{m} \%$, emulsifying agent: E 433

- Natur Nova 2: liquid soil inoculant containing M. anisopliae (hereinafter: NN M. anisopliae); concentration: $1 \times 10^{6}$; pH: $3.9 \pm 0.5$; dry matter content $0.3 \mathrm{~m} / \mathrm{m} \%$; emulsifying agent: E433.

The wireworms that belonged to the Agriotes genus (Col.: Elateridae) were obtained from the infested agricultural field chosen based on symptoms of maize grown on it. After collection, the mixed Agriotes spp. population of wireworms was transferred to plastic vials filled with moist soil and incubated until required for experiments while periodically moisturized by water droplets up to the water-holding capacity of the soil. The wireworm specimens selected for the experiment which ranged from 4 to 13 instar stages with active movement, were kept in wet soil at $22 \pm 4{ }^{\circ} \mathrm{C}$ and $70-90 \%$ rh in a climate chamber (Sufyan et al., 2017).

$S$. granarius were gathered from a culture kept on whole hard wheat under laboratory conditions throughout the experiments at $26 \pm 2{ }^{\circ} \mathrm{C}$ and $60 \pm 7 \%$ (Howe and Hole, 1968) in continuous darkness. Only $<2$ weeks old adults were used in the test.

\section{Bioassay with S. granarius}

These biopreparations were analysed either separately or mixed and administered with or without ash carrier. The assessments were carried out on NN B. bassiana and NN M. anisopliae at the rates of 0,1 and $2 \mathrm{~mL}$ per $\mathrm{kg}$ as well as $1: 1 \mathrm{~mL}$ per $\mathrm{kg}$ mixture of the bioagents (hereinafter: MIX 1:1) on the grains. The laboratory experiments were repeated with ash at the rate of $1 \mathrm{mg}$ per kg applied on the grains in the same setting and dose. Besides, the samples were treated exclusively with ash in order to assess the impact of the carrier on the effectiveness of the insecticides. Each treatment was included in 5 replicates using $200 \mathrm{~g}$ wheat grain.

The even spreading of the biopesticides and carrier in the grain was ensured by thorough 5 minute-mixing. Each sample was placed in a small glass vial; subsequently 50 healthy $S$. granarius adults of both sexes were added, after which the vials were covered with textile wellventilated and placed in incubators at $26 \pm 2{ }^{\circ} \mathrm{C}$ and $60 \pm 7 \% \mathrm{rh}$. Dead adults were counted 7, 14 and 21 days after the addition of the pesticides. After the 21-day count, all adult insects (both dead and alive) were removed from the vials, after which the vials were returned to the incubator for another 45 days. After this period, the emerged S. granarius adults were counted, classified as dead or alive and removed from the vials.

\section{Comparative bioassay with Agriotes larvae}

Tests were done in glass bottles $(9 \mathrm{~cm}$ diameters) containing a sandy loam soil. The soil experiment included two treatments [control and treated with $1 \mathrm{~mL}$ per $\mathrm{kg}$ mixture of Natur Nova 1 and 2 (MIX 1:1)] which contained 5 wireworms per bottle, with four replicates per treatment. After the wireworms were added to bottles, four wheat seeds were sown at a $2.5-\mathrm{cm}$ depth in each bottle. All entomopathogenic mixtures were suspended in $400 \mathrm{~mL}$ of water and applied evenly across the soil surface. Bottles were kept at $22 \pm 4{ }^{\circ} \mathrm{C}$ and $70-90 \%$ rh in a climate chamber. Dead adults were counted after 7, 14 and 21 days. 


\section{Laboratory cultivation of entomopathogenic fungi}

To $1 \mathrm{~g}$ of infected wireworms $9 \mathrm{~mL}$ of peptone saline diluent $(0.1 \%$ weight concentration) was added. The sample was homogenized in a mortar with pestle. From the suspension $0.1 \mathrm{~mL}$ was transferred with a sterile pipette on the previously prepared DRBC (Dichloran rose bengal chloramphenicol) agar plates. The sample was spread on the surface of the agar plates with a spreader. The prepared plates were incubated for 5 days at $25^{\circ} \mathrm{C}$.

\section{Statistical analyses}

Mortality counts were corrected by using Abbott's (1925) formula. The data were analysed by using two-way ANOVA, with weevil mortality as the response variable and exposure time and dose rate of the applied biopesticides as the main effects. Additionally, the putative effect of the ash carrier on the insecticide was statistically evaluated by means of one-way ANOVA using the SPSS 11.5 software. Means were separated by using the Tukey (HSD) test, at $P \leq 0.05$. Significant difference between treated and untreated samples of progeny was evaluated by twosample t-test $(P \leq 0.05)$.

\section{RESULTS}

Mortality of wireworms triggered by bioinoculants was confirmed by our comparative bioassay (Fig. 1). Efficacy of all bioagents increased as a function of the duration of the treatment. In addition, the effects of exposure times on wireworm mortality were statistically proven $(P=$ 0.000). However, no difference was found between the different test species groups.

S. granarius mortalities are shown in Fig. 2. Acceptable efficacy could not be registered in treatments with biopesticides-applied without the carrier (Fig. 2a). Expectably, insect mortality in the samples increased in accordance with the duration of the treatment, whose effect on insect mortality for both doses was statistically confirmed by two-way ANOVA $(1 \mathrm{~mL}$ per $\mathrm{kg}: P=$ 6.34E-17; $2 \mathrm{~mL}$ per $\mathrm{kg}=: P=5.24 \mathrm{E}-21$ ).

The mortality values of all these treatments did not reach 40 percent in one case. After a 7 days-exposure, a dose of $1 \mathrm{mg}$ per $\mathrm{kg} \mathrm{NN} \mathrm{M}$. anisopliae resulted in an average mortality of only $11.84 \%$, which has increased to $34 \%$ over 7 consecutive days.

The effect of different doses on mortality could not be proven in our experiments. with the exception of $\mathrm{NN} \mathrm{B}$. bassiana being administered at the dose of $1 \mathrm{mg}$ per $\mathrm{kg}$, whose insecticide effect at its higher dose was statistically confirmed $(P=0.047)$

No discernible difference could be detected in the case of different bioagent assemblages. A statistically significant difference in the efficacy of entomopathogens of different compositions without carrier could only be demonstrated at the doses of $2 \mathrm{~mL}$ per $\mathrm{kg}(P=0.008)$.

The biological consequences of interaction of bioagent assemblages and their doses on the insecticidal efficacy were not confirmed by two-way ANOVA. The same relationship was found when the interaction of different exposure times and dose were analysed.

The substantial rise in insect mortality caused by the biopesticides with ash carrier could be observed from the $14^{\text {th }}$ day onward (Fig. 2b). The results of insect mortalities were significantly different from those of the treatments in which no carrier was used. The pronounced insect mortalities could be detected in all assemblages and doses. Acceptable efficacy in the view of 


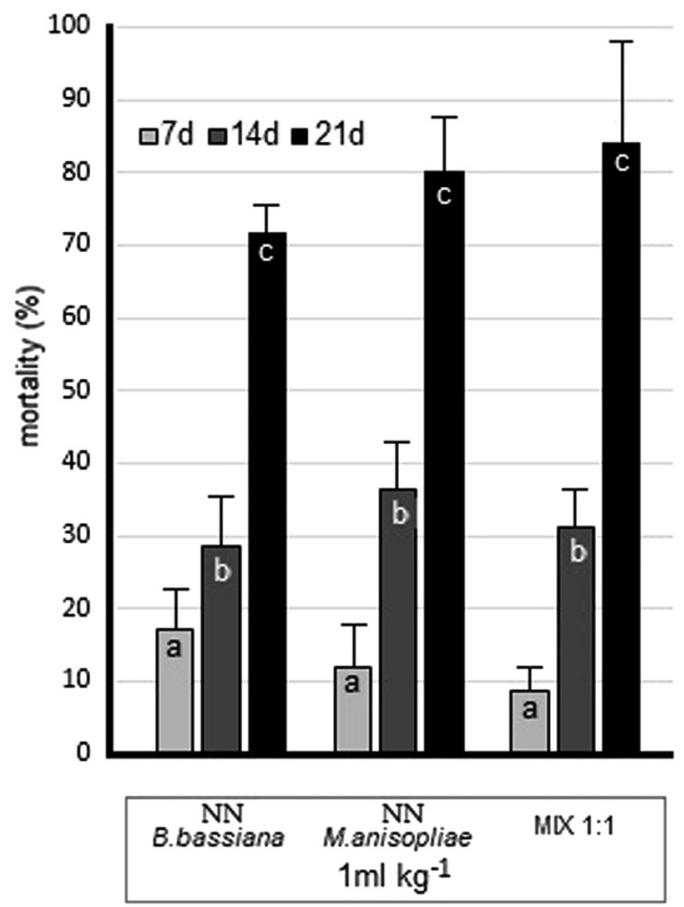

Fig. 1. Abbott corrected percent mortality of wireworms (mean \pm SD) treated with different soil inoculants as a function of exposure times. a, b, c,: small letters indicate significant difference $(P \leq 0.05)$ between means of different mortalities

plant protection practices has already been observed after a 14 days exposure at a dose of 1 mg per $\mathrm{kg}$ MIX 1:1 and at a dose of $2 \mathrm{mg}$ per $\mathrm{kg}$ NN B. bassiana. Total elimination of the experimental insect populations was triggered by both applied doses of MIX 1:1 and $2 \mathrm{~mL}$ per kg NN B. bassiana in 21d. During this exposure time, the insecticidal efficacies have reached $90 \%$ in all applied treatments. The presence of entomopathogens in the perished weevils was confirmed by laboratory cultivation (Figs 3-4). Nevertheless, statistically verifiable differences in the efficiency of the applied biopesticides applied at different doses during exposure time could not be proven. Similarly, no difference between the wheat samples treated with pure ash and those treated with the bioagent-ash mixtures could be observed in any case.

The number and survival rates of progeny are compiled in Table 1. It can be stated that the bioagents applied without carrier have not triggered significant change in the examined parameters of progeny. Significant changes in the number of individuals as compared to the untreated control occurred when $2 \mathrm{mg}$ per $\mathrm{kg} \mathrm{NN}$. B. bassiana $(t=3.061, P=0.037)$ was added, whereas the suppressions of the progeny could be observed invariably in treatments in which the ash carrier was used. The individual numbers and the mortality values of progeny significantly differed from the untreated control after using pure and mixed ash. 


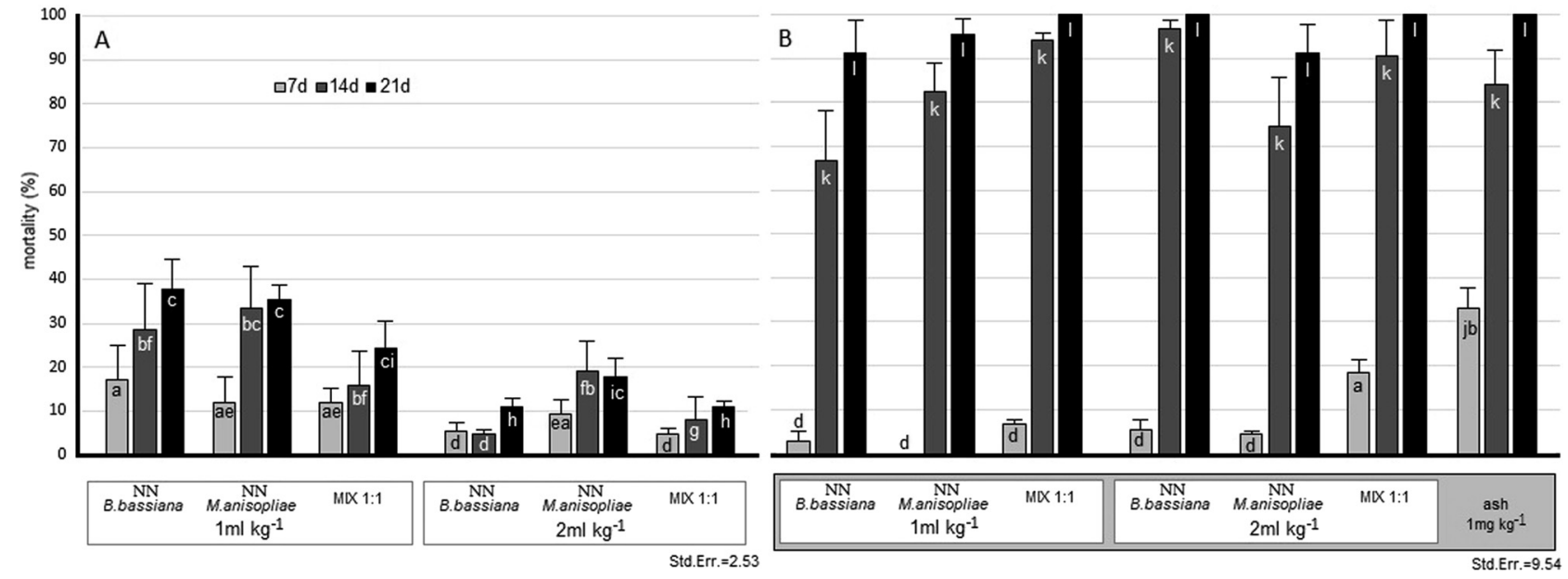

Fig. 2. Abbott corrected percent mortality of $S$. granarius adults (mean $\pm \mathrm{SD}$ ) treated with different soil inoculants as a function of exposure times. a, b, c, d, e, f, g, h, i, j, k, l: small letters indicate significant difference $(P \leq 0.05)$ between means of different mortalities. A) without ash carrier; B) with ash carrier 


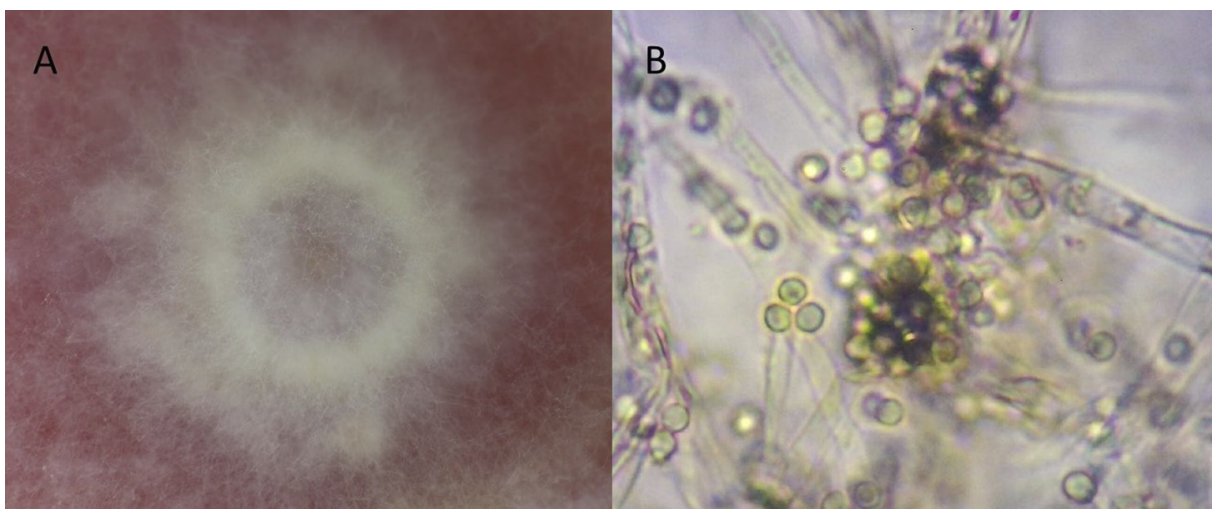

Fig. 3. Colony (A), hyphae and conidia (B) of Beauveria bassiana caused white muscardine disease in the dead insects

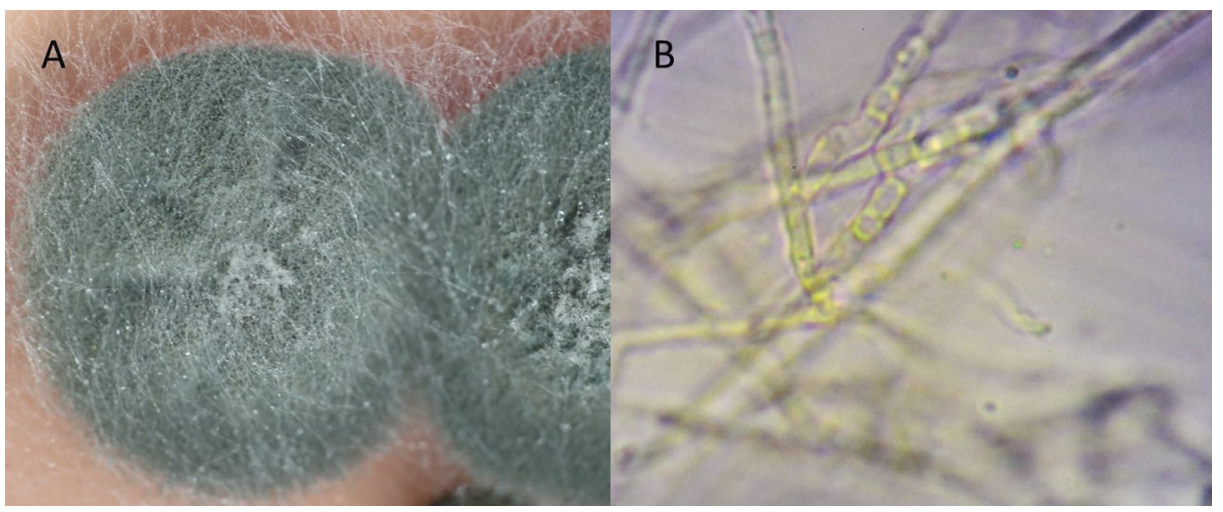

Fig. 4. Colony (A) and hyphae (B) of Metarhizium anisopliae caused green muscardine disease in the dead insects

Table 1. Progeny production of S. granarius (mean number of adults \pm SE) and percentage ( $\% \pm$ SE) of dead progeny on the entomopathogen soil inoculants treated grain, 45 days after the removal of exposed $S$. granarius adults, and the statistic relationships $(P \leq 0.05)$

\begin{tabular}{lccccc}
\hline & & No. progeny & $\%$ dead adults & No. progeny & \% dead adults \\
\hline Control & & $7.75 \pm 0.47$ & $22.17 \pm 9.73$ & & \\
\hline Microfungi rate & & \multicolumn{2}{c}{$1 \mathrm{~mL} \mathrm{~kg}^{-1}$} & \multicolumn{2}{c}{$2 \mathrm{~mL} \mathrm{~kg}^{-1}$} \\
\hline Without ash carrier & NN B.bassiana & $8.75 \pm 3.32$ & $21.11 \pm 9.36$ & $2.75 \pm 1.10$ & $5.00 \pm 5.00$ \\
& NN M. anisopliae & $6.00 \pm 1.47$ & $18.33 \pm 6.87$ & $14.75 \pm 4.46$ & $24.05 \pm 0.65$ \\
& MIX 1:1 & $7.75 \pm 4.53$ & $35.71 \pm 17.97$ & $4.50 \pm 1.50$ & $22.22 \pm 15.71$ \\
With ash carrier & NN B. bassiana & $1.15 \pm 0.22$ & - & - & - \\
& NN M. anisopliae & $2.75 \pm 1.47$ & $1.50 \pm 0.75$ & - & - \\
Ash $\left(1 \mathrm{mg} \mathrm{kg}^{-1}\right)$ & MIX 1:1 & $0.85 \pm 0.25$ & - & - & - \\
\hline
\end{tabular}




\section{DISCUSSION}

B. bassiana and M. anisopliae grow naturally in soils, where these entomopathogenic microfungi are generally effective against soil-dwelling arthropod pests (Erler and Ates, 2015; Chałańska et al., 2017), as it was also confirmed by our experiment. However, the wireworm mortality has not reached 100 percent at the end of our experiment (the average mortality rate was: 78.66\%), which would have been expected to occur after 30 days based on the results of Fernando et al. (2012).

Nevertheless, there are a number of reports on the successful application of these entomopathogens against stored products (Batta, 2004; Athanassiou and Steenberg, 2006; Teshome and Tefera, 2009). and public health pests (Barbarin et al., 2017). Therefore, the evaluated entomopathogens are able to perish some beetle adults, based on literary data (Batta, 2004; Kavallieratos et al., 2014). In contrast, our results confirmed that lack of expected effect of some biopesticides can occur during the usage against the non-target arthropods. The application of the examined ash free bioinoculants Natur Nova containing B. bassiana and M. anisopliae were not suitable for the elimination of the stored product pests modelled by $S$. granarius, despite of the ensuring the wet experimental conditions. In contrast, the expected plant protection efficacy on original target species (Agriotes spp.) of these biopesticides in the recommended environment was affirmed.

Adult-perishing and progeny-suppression of S. granarius caused by the examined biopesticide used together with ash carrier were confirmed by our experiment. This observation was confirmed by several experimental works, whose primary aim was to evaluate the potential insecticide effect of entomopathogen microfungi mixed by diatomaceous earth, ash, chalk powder, charcoal and wheat flour (Hidalgo et al., 1998; Batta, 2004; Athanassiou and Steenberg, 2006). Nevertheless, based on our findings the additive and synergistic insecticide effects of the biopesticides and ash mixture could not be proven.

It is known that the effects of some strains of B. bassiana and M. anisopliae on different target organisms depend on their microclimatic factors, and virulence characteristics (Athanassiou and Steenberg, 2006; Teshome and Tefera, 2009). This phenomenon was confirmed by our experiment because Natur Nova has provided outstanding efficiency against the soil-dwelling organisms, but when applied without carrier it was almost ineffective against stored product pests present on the surface of the grains.

The presence of the carrier is rather important for the effective application of some bioagents. Namely, some microfungi also examined by us can be depicted by intense mycelial growth and sporulation which can help through the extensive surface of these intermediary mediums (Moore and Caudwell, 1997). The influencing consequences of the applied carrier on the weevil mortality would be very desirable in order to the exact description of efficacy of these natural agents.

The insecticide effect of ash also used in our study was previously known (Hakbijl, 2013). The exact conditions (formulation, effective concentration and dose, $\mathrm{pH}$ etc.) of its practical use have been mostly obscure as yet. The determination under laboratory conditions of these unknown parameters is desirable in the future, which can contribute to the extension of the range of sustainable agents used against stored product pests. Based on our results it must be emphasised that the lack of efficacy of some biopesticides can be attributable to the use of pests other than the recommended target organisms. The biopesticides containing fungal 
entomopathogens need more detailed investigations in the next regarding laboratory works which can contribute to the realisation of a more environmental friendly and sustainable stored product protection. In general, these desired efforts correspond to the requirements of integrated pest management (IPM).

\section{ACKNOWLEDGEMENTS}

We thank for providing of bioinoculants to Natur Agro Hungary Ltd. and the financial support to EFOP-3.6.3.-VEKOP-16-2017-00008 and EFOP-3.6.3-VEKOP-16-2017-00005 projects. The project is co-financed by the European Union and the European Social Fund.

\section{REFERENCES}

Abbott, W.S. (1925). A method of computing the effectiveness of an insecticide. Journal of Economic Entomology, 8(2): 265-267.

Athanassiou, C.G. and Steenberg, T. (2006). Insecticidal effect of Beauveria bassiana (Balsamo) Vuillemin (Ascomycota: Hypocreales) in combination with three diatomaceous earth formulations against Sitophilus granarius (L.) (Coleoptera: Curculionidae). Biological Control, 40(3): 411-416.

Barbarin, A.M., Bellicanta, G.S., Osborne, J.A., Schal, C., and Jenkins, N.E. (2017). Susceptibility of insecticide-resistant bed bugs (Cimex lectularius) to infection by fungal biopesticide. Pest Management Science, 73(8): 1568-1573.

Batta, Y.A. (2004). Control of rise weevil (Sitophilus oryzae L., Col.: Curculionidae) with various formulations of Metarhizium anisopliae. Crop Protection, 23(2): 103-108.

Chałańska, A., Bogumił, A., and Danelski, W. (2017). Evaluation of the effectiveness of entomopathogenic fungus Beauveria bassiana (Bals. -Criv.) Vuill. 1912 for the management of Melolontha melolontha (L.) (Coleoptera: Scarabaeidae) and Agriotes lineatus (L.) (Coleoptera: Elateridae). Journal of Research and Applications in Agricultural Engineering, 62(3): 68-71.

Erler, F. and Ates, A.O. (2015). Potential of two entomopathogenic fungi, Beauveria bassiana and Metarhizium anisopliae (Coleoptera: Scarabaeidae), as biological control agents against the June beetle. Journal of Insect Science, 15(1): 44.

Feng, M.G., Chen C., and Chen, B. (2004). Wide dispersal of aphid-pathogenic Entomophthorales among aphids relies upon migratory alates. Environmental Microbiology, 6: 510-516.

Fernando, E.V., Mayling, N.V., Luagngsaard, J.J., and Balckwell, M. (2012). Fungal enthomopathogens. In: Vega, F.E. and Kaya, H.K. (Eds.), Insect Pathology, 2nd ed. Academic Press, pp. 171-220.

Hakbijl, T. (2013). The traditional, historical and prehistoric use of ashes as an insecticide, with an experimental study on the insecticidal efficacy of washed ash. Environmental Archaeology, 7(1): 13-22.

Hidalgo, E., Moore, D., and Le Patourel, G. (1998). The effect of different formulations of Beauveria bassiana on Sitophilus zeamais in stored maize. Journal of Stored Products Research, 34(2-3): 171-179.

Howe, R.W. and Hole, B.D. (1968). The susceptibility of developmental stages of Sitophilus granarius (L.) (Coleoptera, Curculionidae) to moderately low temperatures. Journal of Stored Products Research, 4(2): $147-156$. 
$\mathrm{Hu}, \mathrm{G}$. and St Leger, R.J. (2002). Field studies using a recombinant mycoinsecticide (Metarhizium anisopliae) reveal that it is rhizosphere competent. Applied and Environmental Microbiology, 68(12): 63836387.

Index Fungorum, (2020). Available at: http://www.indexfungorum.org. (Accessed 26 May 2020).

Inglis, G.D., Goettel, M.S., Butt, T.M., and Strasser, H. (2001). Use of hyphomycetous fungi for managing insect pests. In: Butt, T.M., Jackson, C., and Magan, N. (Eds.), Fungi as biocontrol agents. Progress, problems and potential. CABI Publishing, pp. 23-69.

Kavallieratos, N.G., Athanassiou, C.G., Aountala, M.M., and Kontodimas, D.C. (2014). Evaluation of the entomopathogenic fungi Beauveria bassiana, Metarhizium anisopliae and Isaria fumosorosea for control of Sitophilus oryzae. Journal of Food Protection, 77: 87-93.

Meyling, N.V. and Eilenberg, J. (2007). Ecology of the entomopathogenic fungi Beauveria bassiana and Metarhizium anisopliae in temperate agroecosystems: potential for conservation biological control. Biological Control, 43(2): 145-155.

Moore, D. and Caudwell, R.W. (1997). Formulation of entomopathogens for the control of grasshoppers and locust. The Memoirs of the Entomological Society of Canada, 129(S171): 49-67.

Pedrini, N., Ortiz-Urquiza, A., Zhang, S., and Keyhani, N.O. (2013). Targeting of insect epicuticular lipids by the entomopathogenic fungus Beauveria bassiana: hydrocarbon oxidation within the context of a host-pathogen interaction. Frontiers in Microbiology, 4: 24.

Rehner, S.A. (2005). Phylogenetics of the insect pathogenic genus Beauveria. In: Vega, F.E. and Blackwell, M. (Eds.), Insect-Fungal associations: Ecology and evolution. Oxford University Press, pp. 3-27.

Roberts, D.W. and Hajek, A.E. (1992). Entomopathogenic fungi as bioinsecticides. In: Leatham, G.F. (Eds.), Frontiers in industrial mycology. Springer, Boston, MA, pp. 144-159.

Rustiguel, C.B. (2012). Optimization of the chitinase production by different Metarhizium anisopliae strains under solid-state fermentation with silkworm chrysalis as substrate using CCRD. Advances in Microbiology, 2(3): 268-276.

Sufyan, M., Abbasi, A., Dildar Gogi, M., Arshad, M., Nawaz, A., and Neuhoff, D. (2017). Efficacy of Beauveria bassiana for the management of economically important wireworm species (Coleoptera: Elateridae) in organic farming. Gesunde Pflanz, 69(2): 197-202.

Surtees, G. (1965). Effect of grain size on development of the weevil Sitophilus granarius (L.) (Coleoptera: Curculionidae). Proceedings of the Royal Entomological Society of London, Series A, Gen. Entomol. 40(13): $38-40$.

Teshome, A. and Tefera, T. (2009). Susceptibility of Sitophilus zeamais (Motschulski) (Col.: Curculionidae) to Beauveria bassiana and Metarhizium anisopliae. Ethiopian Journal of Science, 32(1): 21-28.

Ulevicius, V., Peciulyte, D., Lugauskas, A., and Andriejauskiene, J. (2004). Field study on changes in viability of airborne fungal propagulesexposed to UV radiation. Environmental Toxicology, 19(4): 437441.

White, J.F., Belanger, F., Meyer, W., Sullivan, R.F., Bischoff, J.F., and Lewis, E.A. (2002). Clavicipitalean fungal epibionts and endophytes- development of symbiotic interactions with plants. Symbiosis, 33(3): 201-213.

Open Access. This is an open-access article distributed under the terms of the Creative Commons Attribution 4.0 International License (https://creativecommons.org/licenses/by/4.0/), which permits unrestricted use, distribution, and reproduction in any medium, provided the original author and source are credited, a link to the CC License is provided, and changes - if any - are indicated. (SID_1) 